Article

\title{
Robust MOF-253-derived N-doped carbon confinement of Pt single nanocrystal electrocatalysts for oxygen evolution reaction
}

\author{
Hellen Gabriela Rivera Monestel a,†, Ibrahim Saana Amiinu a,†, Andrés Alvarado González b, \\ Zonghua $\mathrm{Pu}^{\mathrm{a}}$, BibiMaryam Mousavi ${ }^{\mathrm{b}}$, Shichun $\mathrm{Mu}^{\mathrm{a}}$,* \\ a State Key Laboratory of Advanced Technology for Materials Synthesis and Processing, Wuhan University of Technology, Wuhan 430070, Hubei, China \\ ${ }^{\mathrm{b}}$ School of Chemistry, Chemical Engineering and Life Sciences, Wuhan University of Technology, Wuhan 430070, Hubei, China
}

\section{A R T I C L E I N F O}

\section{Article history:}

Received 6 October 2019

Accepted 23 November 2019

Published 5 May 2020

\section{Keywords:}

$\mathrm{Pt}$

MOF-253

Carbon confinement

Oxygen evolution reaction

Electrocatalyst

\begin{abstract}
A B S T R A C T
Although carbon-supported platinum (Pt/C) is still considered the most active electrocatalyst for hydrogen evolution reaction (HER) and oxygen reduction reaction (ORR), its applications in metal-air batteries as a cathode catalyst, or for oxygen generation via water splitting electrolysis as an anode catalyst is mainly constrained by the insufficient kinetic activity and stability in the oxygen evolution reaction (OER). Here, MOF-253-derived nitrogen-doped carbon (N/C)-confined Pt single nanocrystals (Pt@N/C) have been synthesized and shown to be efficient catalysts for the OER. Even with low Pt mass loading of 6.1 wt\% (Pt@N/C-10), the catalyst exhibits greatly improved activity and long-time stability as an efficient OER catalyst. Such high catalytic performance is attributed to the core-shell structure relationship, in which the active N-doped-C shell not only provides a protective shield to avoid rapid Pt nanocrystal oxidation at high potentials and inhibits the Pt migration and agglomeration, but also improves the conductivity and charge transfer kinetics.
\end{abstract}

(C) 2020, Dalian Institute of Chemical Physics, Chinese Academy of Sciences. Published by Elsevier B.V. All rights reserved.

\section{Introduction}

Currently, the major drawbacks to efficiently drive kinetic processes for electrochemical energy conversion reactions are poor catalytic performance and low utilization rates of electrocatalytic materials. There is an imminent need to improve catalytic activity and stability by using low dosages of catalysts, and adhering to design simplicity and green technology. To achieve these objectives, various electrocatalytic materials with different structures and chemical compositions including noble metals [1,2], low-cost earth-abundant transition metals [3-5], and even metal-free [6-8] materials have been broadly explored as alternative electrocatalysts for various electrochemi- cal applications. Platinum-based materials have played a particularly significant role in this area due to their high activities toward the oxygen reduction reaction (ORR) in fuel cells $[9,10]$ and the hydrogen evolution reaction (HER) in electrolyzers $[11,12]$. However, for efficient electrochemical metal-air batteries and water splitting, the oxygen evolution reaction (OER) also requires a highly active electrocatalyst to lower the electrochemical overpotential. Pt-based electrocatalysts are very efficient for both ORR and HER, and are capable of achieving significant currents close to the thermodynamic potential. However, their relatively low OER activities render them ineffective in practical applications, restricting their use in metal-air batteries and overall water splitting by electrolysis.

\footnotetext{
* Corresponding author. Tel: +86-27-87651837; Fax: +86-27-87879468; E-mail: msc@whut.edu.cn

+ Contributed equally to this work.

This work was supported by the National Natural Science Foundation of China (51672204), and the National Key Research and Development Program of China (2016YFA0202603).

DOI: S1872-2067(19)63488-1 | http://www.sciencedirect.com/science/journal/18722067 | Chin. J. Catal., Vol. 41, No. 5, May 2020
} 
Therefore, other expensive alternatives, such as $\mathrm{IrO}_{2}$ and $\mathrm{RuO}_{2}$ with moderate activities, are typically employed as OER catalysts. Even then, the durability of $\mathrm{IrO}_{2}$ and $\mathrm{RuO}_{2}$ is still insufficient to endure beyond many time-dependent electrochemical cycles. Thus, various methods have been explored to improve the OER performance of Pt-based catalysts, including the dispersion of Pt-crystals on pure carbon supports, high Pt-loading or by alloying with co-active transition metals $[13,14]$. Despite all these efforts, the inability to shield the Pt atoms from direct contact with the electrolyte, or electrochemically induced oxidization often leads to the formation of inactive oxide layers, resulting in significant decline in the OER performance [14]. Despite these challenges, designing a highly active Pt-based OER catalyst with low Pt-loading and enhanced stability via a facile method is essential, if overall water splitting (simultaneous HER/OER) is to be achieved with only Pt-based materials at both, the cathode and the anode, in electrolyzers. Typically, the poor performance of Pt toward OER is largely attributed to the inevitable rapid formation of platinum(II) oxide and platinum(IV) oxide (PtO and $\mathrm{PtO}_{2}$, respectively), which usually occur at the exposed outermost surface layer covering the inter Pt-layers [2,14,15]. Such surface Pt-oxide species, which are in direct contact with the electrolyte, are inactive toward OER thereby hindering maximum Pt utilization and lowering the overall water splitting efficiency. Consequently, the formation of such oxides limits the potential to enhance the OER activity and electrochemical stability of Pt-based catalysts, and must be circumvented. Yet, this remains a very challenging task due to the high reactivity of Pt in alkaline media. To avoid the quick oxidization process and achieve high stability, ultrathin carbon layers have been applied to effectively anchor Pt-metal nanoparticles onto a support matrix or in a core-shell system. Such a strategy has proven to be very efficient for stabilizing and shielding Pt particles against quick oxidization, particle migration and aggregation, thereby leading to improved electrocatalytic performance towards ORR and HER $[2,14,16,17]$. Additionally, both the encapsulating porous carbon layer and support matrix also increase the electrical conductivity and enhance the diffusion of ionic species. Nonetheless, such strategies are still relatively unexploited for enhancing the OER activity and stability of Pt catalysts. In order to further enhance the electrocatalytic OER properties, the use of a highly porous, functionalized carbon matrix, such as a metal organic framework (MOF) is preferable.

MOFs have been recognized as suitable platforms for the preparation of structure-tailored, high surface area nanocarbon frameworks owing to their high flexibility, abundant pores, versatile surface geometry, and high specific surface area [18-23]. Indeed, MOFs are currently being investigated for various emerging applications, including ORR, HER and OER for energy conversion, as well as for supercapacitors and metal-ion/metal-air batteries [18-21]. The direct pyrolysis of MOFs can yield both amorphous and graphitic carbon frameworks and/or an integrated quasi-amorphous carbon structure with graphitic edges. Thus, MOFs are suitable templates for the fabrication of nanoporous carbon materials with high specific surface area including carbon nanotubes, carbon nanorods, graphene, and metal-modified nanocarbon-based materials with immense potential for multifunctional electrochemical applications [18,19,21,22]. Among the sub-classes of MOFs, MOF-253 exhibits a high specific surface area and high porosity, and can be effectively utilized as a suitable template for an even distribution and stabilization of metal species. For such materials, the carbonization of the organic linkers can create porous carbon networks, leading to the formation of catalysts with high specific surface area, uniform distribution of active species and high stability.

In this work, we present the design and facile synthesis of monodispersed single nanocrystal Pt confined by an ultrathin layer of a N-doped carbon framework (Pt@N/C) that addresses both the OER activity and durability issues. Thus, by using MOF-253 as a carbon template, a well-dispersed and highly stabilized Pt single nanocrystal encapsulated in a N-doped carbon framework is synthesized. The encapsulating carbon layer serves as an effective protective sheath for the Pt nanocrystals against electrolyte/electrochemically induced oxidation. This enhances the stability of the Pt core against particle migration and aggregation, as well as improves the conductivity. The carbon layer also provides contact and porous channels for effective diffusion and transport of ionic species. The resulting Pt-N-C framework with highly stabilized and dispersed Pt single nanocrystals and low Pt-loading gives rise to superior OER activity and stability over the commercial counterpart (Pt/C, 20 $w t \%)$, as well as the state-of-the-art $\mathrm{IrO}_{2}$ catalyst. The synthesis route to the monocrystalline Pt-embedded $\mathrm{N}$-doped $\mathrm{C}$ (Pt@N/C) is depicted in Fig. 1. The structure of MOF-253 is composed of one-dimensional chains of hydroxide-bridged octahedrally coordinated $\mathrm{Al}$-cations $\left(\mathrm{Al}^{3+}\right)$ interconnected by 2,2'-bipyridine-5,5'-dicarboxylic acid (bpydc ${ }^{2-}$ ) ligands, resulting in the formation of three-dimensional frameworks with rhombic channels. Typically, MOF-253 is first synthesized and then used as a template for the support carbon framework.

\section{Experimental}

\subsection{Synthesis of Pt@N/C electrocatalysts}

In a typical synthesis, $400 \mathrm{mg}$ of the as-prepared MOF-253 (details provided in Supporting Information) was dispersed

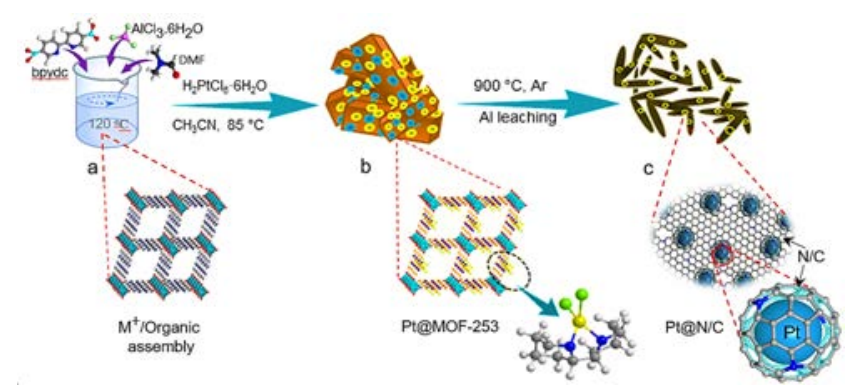

Fig. 1. Schematic illustration of the synthesis of Pt@N/C electrocatalysts. (a) Self-assembly of the metal-organic clusters; (b) Addition of $\mathrm{H}_{2} \mathrm{PtCl}_{6} \cdot 6 \mathrm{H}_{2} \mathrm{O}$ to form Pt@MOF, followed by hydrothermal structural evolution; (c) Carbonization of Pt@MOF into Pt confined N-doped carbon frameworks (Pt@N/C), followed by selective etching of Al-metal residues. 
with a certain amount of $\mathrm{H}_{2} \mathrm{PtCl}_{6} \cdot 6 \mathrm{H}_{2} \mathrm{O}(0.0211,0.0444$, and 0.1 $\mathrm{mg}$ ) in acetonitrile $(15 \mathrm{~mL})$. The obtained solution was then heated at $85{ }^{\circ} \mathrm{C}$ in a Teflon-capped autoclave for $72 \mathrm{~h}$. The formed solids were collected by centrifugation and then immersed in acetonitrile $(15 \mathrm{~mL})$ for 3 days. The solvent was replaced with fresh acetonitrile every $24 \mathrm{~h}$. The products were then collected by filtration and dried at $150{ }^{\circ} \mathrm{C}$ for $12 \mathrm{~h}$ in vacuum. The obtained Pt@MOF-253 solids were then heat-treated at $900{ }^{\circ} \mathrm{C}$ at a ramp rate of $1{ }^{\circ} \mathrm{C} \mathrm{min}-1$ for $4 \mathrm{~h}$ in Ar atmosphere. Finally, the samples were pickled with $\mathrm{NaOH}$ solution at $70{ }^{\circ} \mathrm{C}$ for $6 \mathrm{~h}$ to remove inactive Al-metal species and residues, followed by thorough washing in deionized water until the resultant solution had a neutral $\mathrm{pH}$, before finally being dried under vacuum at $80-110{ }^{\circ} \mathrm{C}$. For simplicity, the as-obtained catalysts were labelled as Pt@N/C- $x$, where $x$ represents 2\%, $5 \%$, and $10 \%$ of Pt-loading in the catalyst.

\subsection{Material characterization}

A JEM-2010FEF high-resolution electron microscope operated at $20 \mathrm{kV}$ was used to obtain the TEM images. X-ray diffraction (XRD) data were recorded on a Rigaku D/MAX-RB diffractometer with monochromatized $\mathrm{Cu}-K_{\alpha}$ radiation, operated at 50 $\mathrm{mA}$ and $40 \mathrm{kV}$. Surface features and morphologies were examined using a JSM-7100F field-emission scanning electron microscope (FE-SEM) installed with an energy-dispersive analyzer and operated at $10 \mathrm{kV}$. Raman spectra were recorded with a LabRAM Aramis Raman equipment using Ar-ion laser at $\lambda=$ $632.8 \mathrm{~nm}$. A VG Multilab 2000 instrument was used to acquire the X-ray photoelectron spectroscopy (XPS) data. Elemental composition was performed using both a German elemental analysis instrument (GmbH EL Cube Vario Elemental Analyzer) and an inductively coupled plasma atomic emission spectrometer (ICP-AES, Optima 4300DV).

\subsection{Electrochemical characterization}

A catalyst-ink was prepared for each sample by ultrasonically dispersing $5.0 \mathrm{mg}$ of catalyst in a solution of $20 \mu \mathrm{L}$ Nafion (5 wt\%, DuPont)/UHP water/isopropanol $(v / v \approx 3 / 7)$ and optimized for homogeneous dispersion. The working electrode was prepared by loading the catalyst ink $(10 \mu \mathrm{L})$ onto a glassy carbon electrode $\left(0.196 \mathrm{~cm}^{2}\right)$ and dried under constant rotation of $600 \mathrm{rpm}$ under ambient conditions. Commercial Pt/C (20 wt\%, $20 \mu \mathrm{g} \mathrm{Pt} \mathrm{cm}^{-2}$ ) and $\mathrm{IrO}_{2}$ were used as benchmark catalysts. $\mathrm{A} \mathrm{Hg} / \mathrm{HgO}$ and graphite plate were used as reference and counter electrodes, respectively. All the experimentally measured potentials were referenced to the standard reversible hydrogen electrode (RHE) according to $E_{\mathrm{RHE}}=E_{\mathrm{Hg} / \mathrm{HgO}}+$ $0.059 \mathrm{pH}+E^{0}$. All electrochemical properties were measured using a three-electrode electrochemical system (CHI660E) at room temperature. The oxygen evolution reaction (OER) properties were characterized in $1.0 \mathrm{M} \mathrm{KOH}$ at a scan rate of 5 $\mathrm{mVs}^{-1}$, and the electrode potential for water oxidation was evaluated at current density of $10 \mathrm{~mA} \mathrm{~cm}^{-2}\left(E_{\mathrm{j}}=10\right)$.

\section{Results and discussion}

\subsection{Structure and composition of catalysts}

SEM images of the as-synthesized MOF-253, before and after pyrolysis, are shown in Fig. S1. It can be observed that the rod-like morphology of the pristine MOF-253 appears to be retained even after carbonization. Fig. 2(a) and (b) show the TEM images of Pt@N/C-10, revealing monodispersed Pt single nanocrystals confined in a N-doped-C framework. The corresponding low-magnification TEM images are presented in Fig. S2. No fingerprint of metallic $\mathrm{Al}$ or its oxides/alloys is observed, which is also confirmed by both XPS and ICP-AES measurements, as shown in Fig. 3(c) and Table S1, respectively. This indicates the complete removal of the inactive $\mathrm{Al}$ species. Fast Fourier-transform (FFT) images taken from the points marked as 1-4 further show that the monodispersed Pt-nanocrystals retained their periodic lattice structures and crystallinity.

The HR-TEM image (Fig. 2(b)) further reveals that such Pt nano-single crystals are well encapsulated in a N-doped carbon framework, $\sim 0.51 \mathrm{~nm}$ in thickness, with a lattice spacing of $0.22 \mathrm{~nm}$ for the Pt (111) facet. Fig. 2(c) shows that the average size of the monodispersed Pt single nanocrystals is $6.7 \mathrm{~nm}$, which is suitable for effective carbon layer encapsulation during pyrolysis. The formation of monodispersed, small, single nanocrystals attests to the existence and effectiveness of confinement in a thin carbon layer. This is also supported by the fact that untethered Pt particles on a carbon support (e.g. commercial $\mathrm{Pt} / \mathrm{C}$ ) have a high tendency to freely aggregate into larger particles during thermal treatments, which are less active catalysts $[2,16,17]$. The high degree of clarity seen in the crystal lattices is also an indication of an ultrathin carbon layer encapsulation, because thicker layers or many carbon layers would normally mask the transparency of the Pt-lattices and limit accessibility of the electrolyte to the active Pt underneath $[2,16,17]$. In a series of control experiments, catalyst samples including Pt-free $\mathrm{N}$-doped carbon (N/C), $\mathrm{N}$-free Pt/C and similar Pt@N/C- $x$ catalysts with different Pt and $\mathrm{N}$ loadings were also evaluated, to understand the structure-property correlation and its effect on catalytic performance. As shown in Figs. S3 and S4, the average particle size of Pt@N/C-10 $(\sim 6.7 \mathrm{~nm})$ is smaller than that of Pt@N/C-2 ( 9.6 nm) and Pt@N/C-5 ( 8.5
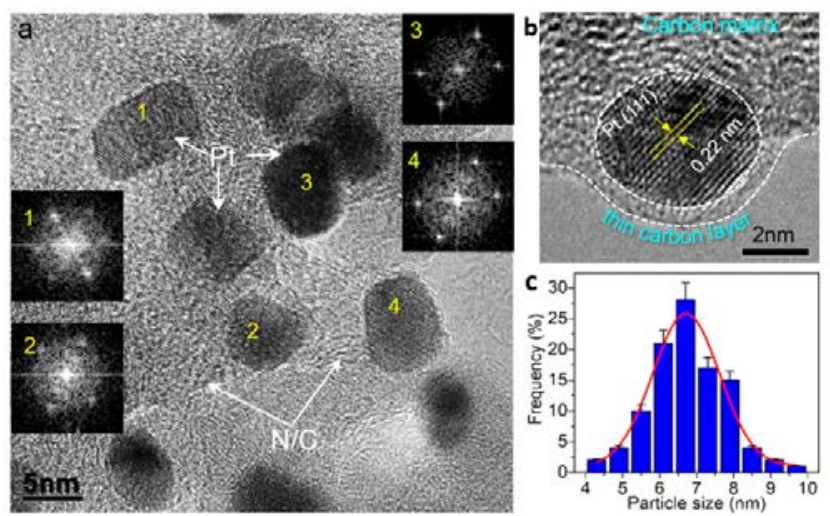

Fig. 2. Microstructures of Pt@N/C-10. (a) TEM image of Pt@N/C-10. Images 1-4 are the corresponding fast Fourier transforms (FFT); (b) HR-TEM image revealing a Pt lattice of spacing $\approx 0.22 \mathrm{~nm}$; (c) Particle size distribution of Pt@N/C-10, average particle size is $\approx 6.7 \mathrm{~nm}$. 

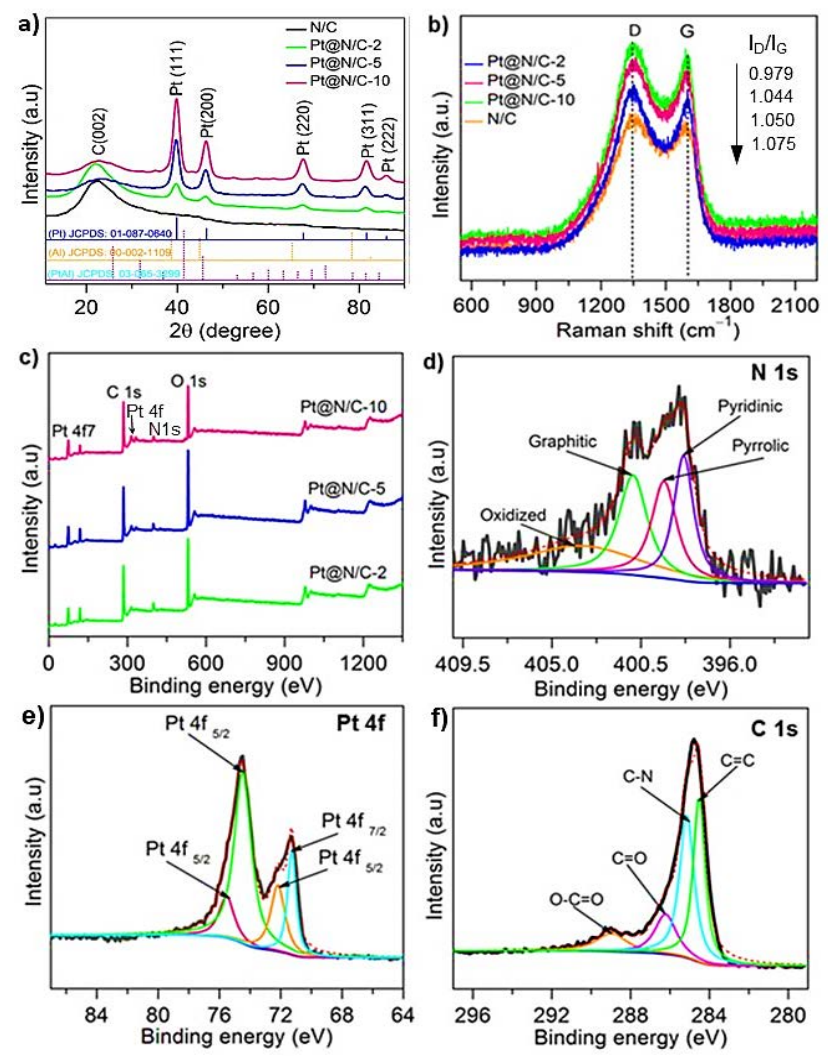

Fig. 3. (a) XRD patterns; (b) Raman spectra with corresponding $I_{\mathrm{D}} / I_{\mathrm{G}}$ ratio.XPS spectra of Pt@N/C-10. (c) survey; (d) N 1s; (e) Pt 4f; (f) C $1 s$.

$\mathrm{nm})$, based on the corresponding TEM analyses.

XRD patterns of the Pt@N/C-based samples (Fig. 3(a)) appear to be similar, exhibiting increased peak intensities as the Pt content increases, suggesting that they have similar crystalline properties (JCPDS: 01-087-0640). Meanwhile, the XRD pattern of the carbonized MOF-253 without Pt (Pt-free N/C) matches well with that of a typical $\mathrm{N}$-doped carbon framework $[8,18,19,21]$, confirming the complete transformation of the pristine MOF-253 into an N-doped carbon (N/C) structure. Typically, the diffraction peaks at $39.8^{\circ}, 46.4^{\circ}, 67.7^{\circ}, 81.7^{\circ}$, and $86.0^{\circ}$ are attributed to the Pt (111), (200), (220), (311) and (222) crystal planes, respectively. This indicates a typical crystalline Pt phase with a face-centered-cubic (fcc) structure. It is worth noting that the lattice indices of Pt@N/C-10 also match well with that of Pt/C (Fig. S5), suggesting that the $\mathrm{N}$-doping and/or carbon encapsulation have no effect on the lattice structure of the active Pt core.

Raman spectra were recorded in order to study the configuration and structural defects of the synthesized catalysts. As shown in Fig. 3(b), all samples display two main peaks at $\sim 1349.95$ and $\sim 1597.95 \mathrm{~cm}^{-1}$, which are assigned to the D and $\mathrm{G}$ bands, respectively. The D-band is attributed to lattice defects, while the G-band is ascribed to $s p^{2}$-hybridized carbon $[7,13,16]$. The ratio of the band intensities $\left(I_{\mathrm{D}} / I_{\mathrm{G}}\right)$ is found to be $\sim 0.979,1.044,1.050$ and 1.075 for Pt@N/C-2, Pt@N/C-5, $\mathrm{Pt} @ \mathrm{~N} / \mathrm{C}-10$ and N/C, respectively, signifying that nitrogen doping and integration of metallic Pt induced an increase in the number of carbon lattice defects $[17,20]$. In comparison to
Pt@N/C-2 and Pt@N/C-5, the higher N and Pt loading of Pt@N/C-10 is considered significant for enhancing overall catalytic activity.

XPS was used to analyze the surface chemical composition, as well as the binding energies associated with the various atomic species. The survey scan (Fig. 3(c)) shows the presence of all elemental components, including Pt, $\mathrm{C}, \mathrm{N}$ and $\mathrm{O}$. Metallic-Al or its alloys were not detected, further confirming the complete removal of $\mathrm{Al}$ residues from the samples by the pickling process. Removal of the $\mathrm{Al}$ species leads to the creation of more porous structures, which is known to improve diffusion properties and catalytic activity. The high resolution N1s peak is resolved into four subpeaks, assignable to pyridinic- $\mathrm{N}$ (398.34 eV), graphitic-N (400.89 V), Pyrrolic-N (399.33 eV) and oxidized-N (403.46 eV) species, respectively (Fig. 3(d)). Graphitic- $\mathrm{N}$ is considered to improve the diffusion-limited properties, while the pyridinic- $\mathrm{N}$, as an active site for OER, raises the onset potential, electrical conductivity and surface wettability $[7,21,25,26,27]$. Several studies have also reported that the pyridinic- $\mathrm{N}$ site can accept electrons from neighboring $\mathrm{C}$ atoms, making possible the adsorption of water oxidation intermediates $\left(\mathrm{OH}^{-}, \mathrm{OOH}^{-}\right)$as the rate defining steps for OER in alkaline solutions [25,26]. Metal-induced reactions during thermal treatments can avail high structural defects as suitable sites for $\mathrm{N}$-doping. As displayed in Table S4, Pt@N/C-10 shows the highest proportion of combined pyridinic- $\mathrm{N}$ and graphitic- $\mathrm{N}$ species, which, coupled with the optimal Pt-loading, is expected to enhance catalytic activity over all the other catalyst samples.

The above Raman spectra also show the presence of defects in the carbon lattices for all samples, which is beneficial for further enhancement of catalytic properties. The deconvoluted Pt $4 f$ peak (Fig. 3(e)) shows four subpeaks constituting two pairs of doublets, with weak peak intensities. The two peaks at 71.28 and $74.58 \mathrm{eV}$ are attributed to Pt $4 f_{7 / 2}$ and Pt $4 f_{5 / 2}$ excitations of metallic $\mathrm{Pt}$, respectively, whereas the peaks at 72.18 and $75.58 \mathrm{eV}$ are ascribed to oxidized Pt $[2,13]$. The deconvoluted C $1 s$ peak (Fig. 3(c)) displays subpeaks associated with $s p^{2}$-hybridized C=C $(\sim 284.5 \mathrm{eV}), \mathrm{C}-\mathrm{N}(\sim 285.2 \mathrm{eV}), \mathrm{C}=\mathrm{O}(\sim 286.3$ $\mathrm{eV})$ and $\mathrm{O}-\mathrm{C}=\mathrm{O}(\sim 288.9 \mathrm{eV})$ species [20,21]. The corresponding deconvoluted C, N and Pt subpeaks for Pt@N/C-2 and $\mathrm{Pt} @ N / C-5$ are shown in Fig. S6 and S7, respectively.

\subsection{Electrocatalytic OER performance}

Given the importance and urgent need to enhance the OER performance of Pt-based materials, the electrocatalytic activity of all catalyst samples was probed by using a standard three-electrode cell setup in $1.0 \mathrm{M} \mathrm{KOH}$ solutions at a scan rate of $5 \mathrm{mV} \mathrm{s}^{-1}$. Linear sweep voltammetry (LSV) was employed to generate the polarization curves (Fig. 4(a)) for all catalyst samples after iR corrections. The catalyst sample with a Pt-loading of $6.1 \mathrm{wt} \%$ (Pt@N/C-10) is found to exhibit the best OER activity. To achieve a current density of $10 \mathrm{~mA} \mathrm{~cm}-2$, the catalysts require a potential as low as $\sim 1.564, \sim 1.544$, and $\sim 1.528 \mathrm{~V}$ for Pt@N/C-2, Pt@N/C-5 and Pt@N/C-10, respectively. It is worth noting that the OER activity of the best sample (Pt@N/C-10, with an onset overpotential, $\eta \approx 298 \mathrm{mV}$ ) is about $55 \mathrm{mV}$ lower 

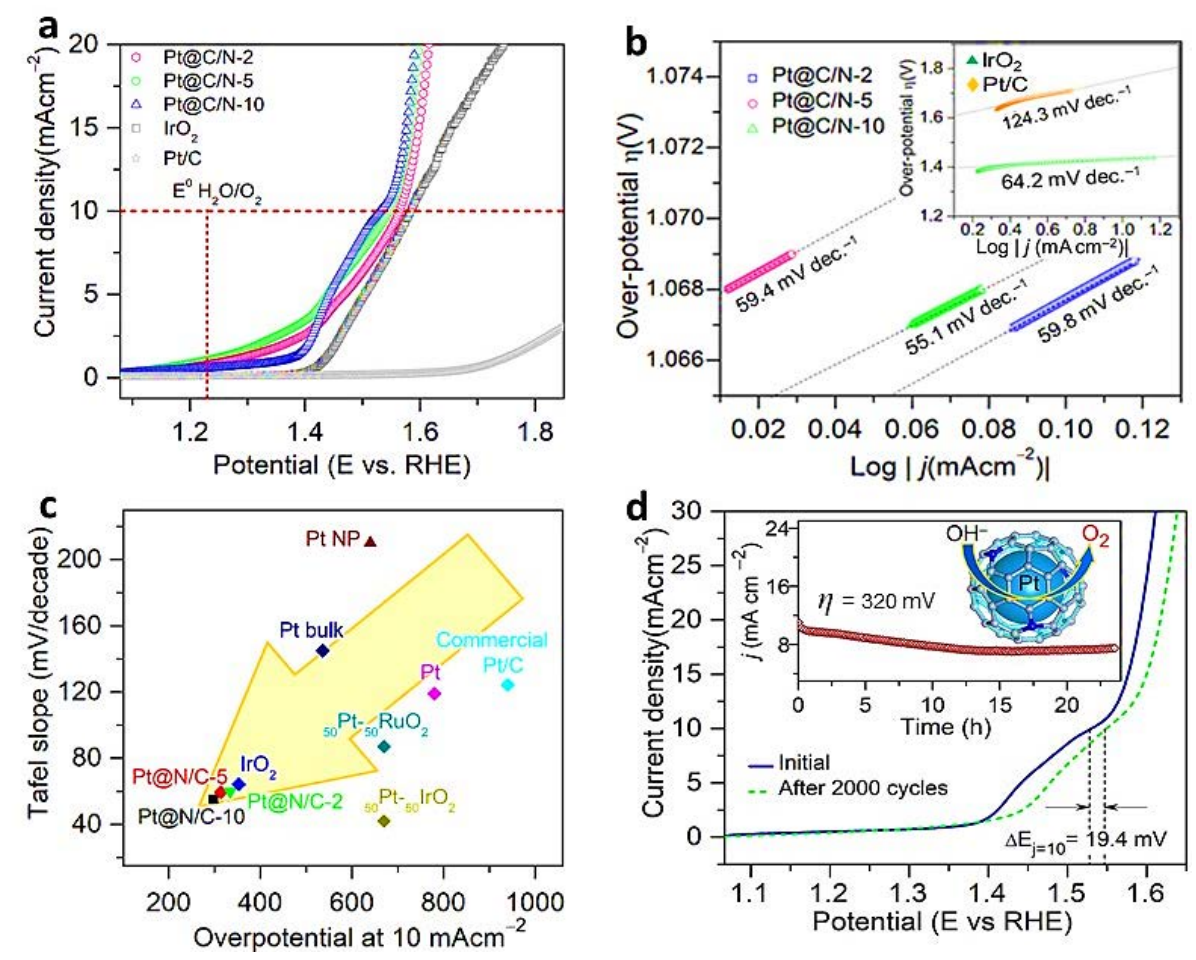

Fig. 4. (a) OER polarization curves of catalyst samples; (b) Tafel slopes; (c) Comparison of the OER activity of this work with other precious metal-based catalyst, references are detailed in Table S5; (d) Polarization curves before and after 2000 accelerated potential sweeps of Pt@N/C-10. Insert is the $i$ - $t$ stability test at constant overpotentials.

than that of the benchmark catalyst $\left(\mathrm{IrO}_{2}, \eta \sim 353 \mathrm{mV}\right)$, and is clearly superior to the $\mathrm{N}$-free carbon commercial catalyst $(\mathrm{Pt} / \mathrm{C})$, as well as the Pt-free N-doped carbon (N/C) catalyst, as shown in Fig. S8.

The OER kinetic activity was also probed by analyzing the Tafel slopes. As shown in Fig. 4(b), the Tafel slopes of Pt@N/C-2, Pt@N/C-5, and Pt@N/C-10 are 59.8, 59.4 and 55.1 $\mathrm{mV} \mathrm{dec}{ }^{-1}$, respectively, which are also smaller than that of the benchmark catalysts $\left(\mathrm{IrO}_{2} \sim 64.2 \mathrm{mV} \mathrm{\textrm {dec } ^ { - 1 }}\right.$, and commercial $\mathrm{Pt} / \mathrm{C} \sim 124.3 \mathrm{mV} \mathrm{dec}^{-1}$ ), further demonstrating the high-performance electrocatalytic ability of Pt@N/C toward OER. Interestingly, as shown in Fig. 4(c), the catalytic activity of Pt@N/C is superior to the noble metal-based catalysts, as well as transition metal-based OER catalysts (Table S5).

An important consideration for the application of such Pt-based materials is their time-dependent electrochemical durability. As shown in the inset of Fig. 4(d), Pt@N/C-10 demonstrates good stability even after more than $20 \mathrm{~h}$ of continuous electrochemical scanning. However, a slight gradual drop in current is observed for the initial $10 \mathrm{~h}$, which can be attributed to the inevitable surface oxidation due to exposure to the strongly oxidizing environment of the electrolyte and also, due to the electrochemical current during the scan process, consistent with the LSV scan results. However, the catalyst gradually stabilizes and then remains fairly stable thereafter, indicating that the unavoidable surface oxidation process is not pervasive over the catalyst structure to significantly affect its electrochemical activity. Interestingly, the catalyst is also found to maintain its high activity after being subjected to an accelerated degradation test (ADT) for 2000 cycles (Fig. 4(d)) and is, additionally, found to be superior to the fresh benchmark catalyst (Pt/C), further indicating that Pt@N/C-10 can sustain a current density of $10 \mathrm{~mA} \mathrm{~cm}-2$ with only a small potential degradation of $\sim 19.4 \mathrm{mV}$. However, the benchmark $\mathrm{IrO}_{2}$ deteriorates by $\sim 23.3 \mathrm{mV}$ at the same rate at $10 \mathrm{~mA} \mathrm{~cm}^{-2}$ (Fig. S9).

To further evaluate the stability of the catalyst itself, we conducted both TEM (Fig. S10) and XPS (Fig. S11) investigations of Pt@N/C-10 after an accelerated durability test (ADT). The TEM observations of the catalyst structure indicate that the Pt nanocrystals continue to be well-dispersed in the catalyst, without any significant migration, or aggregation, owing to the robust thin-carbon entrapment. However, a slight fading of the Pt-lattices is observed due to the inevitable oxidization. Also, there is no significant change in position of the Pt $4 f$ peaks or appearance of any new phase peaks, according to the XPS survey scan, which suggests that the chemical structure is very stable. However, the intensity of the Pt $4 f$ peaks are reduced considerably (almost to the point of disappearance), with a corresponding slight increase in the intensity of the oxygen and carbon peaks. This can be attributed to the following reasons. (1) Long-term exposure of the catalyst to the concentrated electrolyte inevitably induces oxidation of the Pt particles, thereby increasing the content of oxidized-Pt species, and (2) the long exposure to concentrated electrolyte could also minimally leach out Pt species from the catalyst, leading to reduced content of metallic-Pt (Pt active site). The electrochemically induced oxidation and reduced content of metallic-Pt can be established from the XPS near-surface scan (Fig. S9), which displays a slight increase in the intensity of the oxygen peak after electrochemical ADT. Regardless of any of these unavoid- 
able phenomena, the catalyst clearly demonstrates high chemical stability, without the formation of any new species that could significantly affect its structure or overall catalytic performance.

Generally, the poor OER performance of $\mathrm{Pt} / \mathrm{C}$ is mainly attributed to the inevitable and rapid oxidization of the Pt nanoparticles on the carbon support. Surface-dispersed Pt nanoparticles are highly susceptible to oxidation, particle migration and coalescence. Such quickly oxidized Pt species are inactive toward OER, while the migration and agglomeration of Pt nanoparticles result in Pt-carbon detachment which, in turn, promotes the formation of larger particles, leading to a decrease in surface area and number of active sites. This explains why commercial $\mathrm{Pt} / \mathrm{C}$ is a poor OER catalyst. However, in the protective structure of Pt@N/C-10, the activity originates in activated Pt sites that selectively bind with $\mathrm{OH}^{-}$species. According to previous research $[14,28,29]$, for oxygen evolution on Pt in alkaline media, the formation of $\mathrm{Pt}-\mathrm{OH}_{\text {ads }}$ phase is promoted by the nucleophilic attack of hydroxide ions on the Pt-metal surface, followed by a fast electron transfer to the metastable configuration where $\mathrm{OH}$ is chemisorbed on the 'activated' Pt-site. The hydroxyl group is then selectively adsorbed on the Pt sublayer to form $\mathrm{Pt}-\mathrm{OH}_{\mathrm{ads}}$ as an active phase. Here, the $\mathrm{N}$-doped carbon, which is often employed as a modified carbon support [30], robustly confines the Pt single nanocrystal growth, migration and dissolution. It also provides auxiliary defect-based active sites to impart high activity to the integrated Pt-N-C catalyst framework without blocking access to the interior active sites on Pt due to its interconnected pore structures, which promote efficient diffusion. The significant oxidation of the carbon support at high OER potentials can also be alleviated due to the protection offered by the graphitic outer shell. Thus, the thin carbon layer encapsulation is sufficient to deter the Pt nanocrystal migration and agglomeration, and also reduces the rate of nanocrystal oxidization and helps to maintain a high surface area.

The N-doping in the carbon framework also confers catalytic advantages to Pt@N/C-10 over commercial Pt/C. The defects presented in the N/C framework aid in the catalytic activity while the high porosity, from the pristine MOF-253 and subsequent removal of $\mathrm{Al}$, allows for efficient diffusion and transport of ionic species. In addition, the higher electronegativity of oxygen, as compared to carbon, and the strong electron affinity of doped-N atoms lead to the creation of positively charged neighboring $\mathrm{C}$-atoms as active sites $[16,18,21]$. The improved OER activity of Pt@N/C could also be attributed to the enhanced adsorption of $\mathrm{OH}^{-}$and efficient transport of intermediate oxygen-containing products such as peroxides $\left(\mathrm{O}_{2}{ }^{2-}\right)$ and superoxides $\left(\mathrm{O}^{2-}\right)$. Furthermore, previous reports show that the $\mathrm{Pt} / \mathrm{OH}^{-}$surface binding energy is lowered by the high positive potential at the electrode surface, while the high $\mathrm{pH}$ (14) of the electrolyte lowers the electrochemical potential $[15,16]$. This can favor the adsorption of $\mathrm{OH}^{-}$, as well as the activation of the Pt surface, followed by transfer of electrons and subsequent formation of surface $\mathrm{Pt}-\mathrm{OH}$ species $[15,28,29]$. The surface coupling and deprotonation of the adsorbed hydroxyl groups result in the efficient evolution of oxygen.
The conductivity of the catalysts, which is important to their application, was also verified. As shown in the Nyquist plots (Fig. S12), Pt@N/C-10 exhibits a lower charge transfer resistance $(\sim 140.95 \Omega)$ than Pt/C $(\sim 302.68 \Omega)$. This indicates that the catalytic activity of Pt@N/C-10 is further improved by the optimal $\mathrm{N}$-doping [31-33] and the thin carbon layer confinement of the Pt core, enhancing the charge transfer and electrical conductivity properties in comparison to those of Pt/C.

\section{Conclusions}

To summarize, our study suggests that Pt@N/C can be facilely synthesized and demonstrates that it can be used as a highly active electrocatalyst with enhanced kinetic activity and stability toward the oxygen evolution reaction (OER). In contrast to commercial catalysts such as $\mathrm{IrO}_{2}$ and $\mathrm{Pt} / \mathrm{C}$, it is clearly established that monodispersed Pt single nanocrystals (with sizes $\sim 6.7 \mathrm{~nm})$ confined in a thin carbon layer $(\sim 0.51 \mathrm{~nm}$ thick) constitute a very efficient catalyst which exhibits excellent OER performance ( 1.528 V@10 mA cm-2), with minimal degradation of the potential even after 2000 cycles and good potential retention. This simple confinement technique allows for the preparation of electrocatalysts with greatly reduced Pt loading, that can potentially exhibit superior OER performance in comparison to expensive and relatively unstable commercial counterparts (Pt/C $20 \mathrm{wt} \%$ and $\mathrm{IrO}_{2}$ ). This work is expected to inspire the redesign of Pt-based materials to be used as efficient electrocatalysts for OER, while lowering the cost of using different electrode materials for hydrogen production via water splitting.

\section{Acknowledgments}

We gratefully acknowledge the National Natural Science Foundation of China (51672204), and the National Key Research and Development Program of China (2016YFA0202603) for the funding support.

\section{References}

[1] S. Ghosh, R. N. Basu, Nanoscale, 2018, 10, 11241-11280.

[2] S. Chen, Z. Wei, X. Q. Qi, L. Dong, Y. G. Guo, L. Wan, Z. Shao, L. Li, J. Am. Chem. Soc., 2012, 134, 13252-13255.

[3] X. Liu, I. S. Amiinu, S. Liu, Z. Pu, W. Li, B. Ye, D. Tan, S. Mu, Adv. Mater. Interfaces, 2017, 4, 1601227

[4] S. Xie, F. Li, S. Xu, J. Li, W. Zeng, Chin.J. Catal., 2019, 40, 1205-1211.

[5] L. Peng, S. S. A. Shah, Z. Wei, Chin. J. Catal., 2018, 39, 1575-1593.

[6] J. W. Zhu, Y. P. Huang, W. C. Mei, C. Y. Zhao, C. T. Zhang, J. Zhang, I. S. Amiinu, S. C. Mu, Angew. Chem. Int. Ed., 2019, 58, 3859-3864.

[7] M. Ye, C. Li, Y. Zhao, L. Qu, Carbon, 2016, 106, 9-19.

[8] I. S. Amiinu, J. Zhang, Z. Kou, X. Liu, O. K. Asare, H. Zhou, K. Cheng, H. Zhang, L. Mai, M. Pan, S. Mu, ACS Appl. Mater. Interfaces, 2016, 8, 29408-29418.

[9] H. Wu, T. Peng, Z. K. Kou, J. Zhang, K. Cheng, D. P. He, M. Pan, S. Mu, Chin. J. Catal., 2015, 36, 490

[10] K. Jiang, D. D. Zhao, S. J. Guo, X. Zhang, X. Zhu, J. Guo, G. Lu, X. Q. Huang, Sci. Adv., 2017, 3, 1601705/1-1601705/8. 


\title{
Graphical Abstract
}

Chin. J. Catal., 2020, 41: 839-846 doi: S1872-2067(19)63488-1

Robust MOF-253-derived N-doped carbon confinement of Pt single nanocrystal electrocatalysts for oxygen evolution reaction

Hellen Gabriela Rivera Monestel, Ibrahim Saana Amiinu, Andrés Alvarado González, Zonghua Pu, BibiMaryam Mousavi, Shichun $\mathrm{Mu}^{*}$ Wuhan University of Technology

By using MOF-253 as a carbon template, a well-dispersed and highly stabilized Pt single nanocrystal confined in a N-doped carbon framework is synthesized, and exhibits a superior OER activity and stability over $\mathrm{IrO}_{2}$ catalysts.

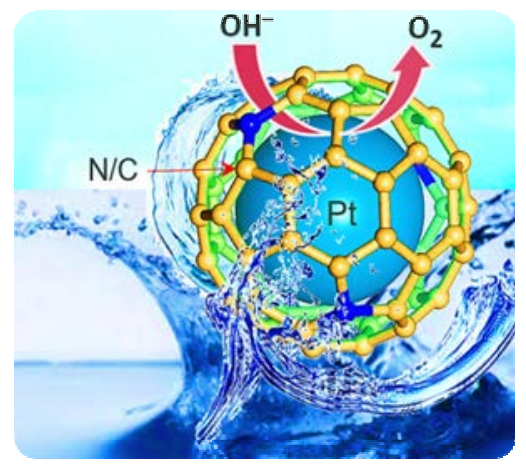

[11] S. H. Ye, F. Y. Luo , Q. L. Zhang, P. Y. Zhang, T. T. Xu, Q. Wang, D. S. He, L. C. Guo, Y. Zhang, C. X. He, X. P. Ouyang, M. Gu, J. H. Liu, X. L. Sun, Energy Environ. Sci., 2019, 12, 1000-1007.

[12] J. Liu, Q. Ma, Z. Huang, G. Liu, H. Zhang, Adv. Mater., 2019, 31, 1800696

[13] M. Favaro, C. Valero-Vidal, J. Eichhorn, F. M. Toma, P. N. Ross, J. Yano, Z. Liu, E. J. Crumlin, J. Mater. Chem. A, 2017, 5, 11634-11643.

[14] D. Sun, Y. Zhao, H. Su, W. Li, Chin. J. Catal., 2013, 34, 1434-1442.

[15] M. Favaro, C. Valero-Vidal, J. Eichhorn, F. M. Toma, P. N. Ross, J. Yano, Z. Liugh, E. J. Crumlin, J. Mater. Chem. A, 2017, 5, 11634-11643.

[16] Y. Nie, S. Chen, W. Ding, X. Xie, Y. Zhang, Z. Wei, Chem. Commun., 2014, 50, 15431-15434.

[17] K. Cheng, Z. Kou, J. Zhang, M. Jiang, H. Wu, L. Hu, X. Yang, M. Pan, S. $\mathrm{Mu}$, J. Mater. Chem. A, 2015, 3, 14007-14014.

[18] I. S. Amiinu, X. Liu, Z. Pu, W. Li, Q. Li, J. Zhang, H. Tang, H. Zhang, S. $\mathrm{Mu}$, Adv. Funct. Mater., 2018, 28, 1704638.

[19] B. Liu, H. Shioyama, H. Jiang, X. Zhang, Q. Xu, Carbon, 2010, 48, 456-463.

[20] X. He, F. Yin, H. Wang, B. Chen, G. Li, Chin. J. Catal., 2018, 39, 207-227.

[21] I. S. Amiinu, Z. Pu, X. Liu, K. A. Owusu, H. G. R. Monestel, F. O. Boakye, H. Zhang, S. Mu, Adv. Funct. Mater., 2017, 27, 1702300.
[22] J. R. Long, O. M. Yaghi, Chem. Soc. Rev., 2009, 38, 1213-1214.

[23] E. D. Bloch, D. Britt, C. Lee, C. J. Doonan, F. J. Uribe-Romo, H. Furukawa, J. R. Long, O. M. Yaghi, J. Am. Chem. Soc., 2010, 132, 14382-14384.

[24] Y.-P. Wu, W. Zhou, J. Zhao, W.-W. Dong, Y.-Q. Lan, D.-S. Li, C. Sun, X. Bu, Angew. Chem., 2017, 129, 1-6.

[25] H. B. Yang, J. Miao, S. F. Hung, J. Chen, H. B. Tao, X. Wang, L. Zhang, R. Chen, J. Gao, H. M. Chen, L. Dai, B. Liu, Sci. Adv., 2016, 2, 1501122/1-1501122/11.

[26] Y. Zhao, R. Nakamura, K. Kamiya, S. Nakanishi, K. Hashimoto, Nat. Commun., 2013, 4, 2390.

[27] L. Zhao, X.-L. Sui, Q.-Y. Zhou, J.-Z. Li, J.-J. Zhang, G.-S. Huang, Z.-B. Wang, J. Mater. Chem. A, 2018, 6, 6212-6219

[28] A. Damjanovic, A. Dey, J. O. M. Bockris, Electrochim. Acta, 1966, 11, 791-814.

[29] V. I. Birss, A. Damjanovic, J. Electrochem. Soc., 1987, 134, 113-117.

[30] J. Liu, W. Q. Li, R. L. Cheng, Q. Wu, J. H. Zhao, D. P. He, S. C. Mu, Langmuir, 2019, 35, 2580-2586.

[31] D. Bhattacharjya, H.-Y. Park, M.-S. Kim, H.-S. Choi, S. N. Inamdar, J.-S. Yu, Langmuir, 2014, 30, 318-324.

[32] L. Zhao, X. L. Sui, J. Z. Li, J. J. Zhang, L. M. Zhang, G. S. Huang, Z. B. Wang, Appl. Catal. B, 2018, 231, 224-233.

[33] L. Zhao, X. L. Sui, J. L. Li, J. J. Zhang, L. M. Zhang, Z. B. Wang, ACS Appl. Mater. Interfaces, 2016, 8, 16026-16034.

\section{利用MOF-253衍生氮掺杂碳限域效应促进Pt纳米单晶电催化剂的氧析出反应}

\author{
Hellen Gabriela Rivera Monestel ${ }^{\mathrm{a}, \dagger}$, Ibrahim Saana Amiinu ${ }^{\mathrm{a}, \dagger}$, Andrés Alvarado González ${ }^{\mathrm{b}}$, 蒲宗华 ${ }^{\mathrm{a}}$, \\ BibiMaryam Mousavi ${ }^{\mathrm{b}}$ ，木士春 ${ }^{\mathrm{a},{ }^{*}}$ \\ a武汉理工大学材料复合新技术国家重点实验, 湖北武汉 430070

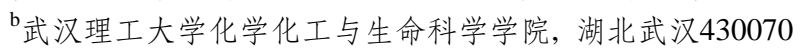

摘要: 目前, 为了有效解决电化学能量转化反应动力学过程缓慢和商业化应用等问题, 需要大力提高催化剂的电催化活性
和稳定性, 并大幅降低贵金属催化剂的用量. 通常, 铂(Pt)基催化剂对燃料电池的氧还原反应(ORR)和水电解过程的氢析出
反应(HER)表现出很高的活性. 然而, 对于高效的金属-空气电池和水电解装置, 其中的氧析出反应(OER)则需要高活性的
非Pt电催化剂来降低电化学过电位及提高其对高电位的耐受性. 虽然相较于Pt催化剂, $\mathrm{IrO}_{2}$ 和RuO $\mathrm{O}_{2}$ 等贵金属催化剂表现出
了更高的OER活性, 然而, 它们的稳定性差, 难以满足实际应用需求, 严重阻碍了其在金属-空气电池和水电解中的应用. 通
常, Pt对OER的低效催化主要归因于在OER 电催化过程中 $\mathrm{Pt}$ 与电解液直接接触, 导致 $\mathrm{Pt}$ 表面快速被氧化, 形成Pt氧化物 
$\left(\mathrm{Pt}^{+4} \mathrm{O}_{2}\right.$ 和 $\left.\mathrm{Pt}^{+2} \mathrm{O}\right)$ 层. 形成的 $\mathrm{Pt}$ 氧化物对 OER不起催化作用, 从而降低了 $\mathrm{Pt}$ 的利用率和总的水电解效率.

为了避免P $\mathrm{P}$ 表面的快速氧化, 实现高的OER性能, 我们将Pt金属纳米粒子有效地限域在超薄功能多孔碳层内. 前期, 已 有大量的有关金属基ORR和HER催化剂研究证明,这种策略对于稳定金属纳米颗粒非常有效, 可有效避免金属催化剂的快 速氧化, 而且还可抑制金属颗粒迁移和团聚; 此外, 还有利于增强催化剂的导电性和离子物种的扩散能力, 从而提高催化 剂的电催化性能. 然而, 要达到提高金属催化剂OER电催化性能的目的, 还需要设计一种具有优良结构的功能化异质原子 掺杂多孔碳基限域材料. 金属有机框架(MOF), 特别是MOF-253, 由于具有较高的柔韧性、丰富的孔、可控的几何结构和高 比表面积, 被认为是制备功能多孔碳基限域材料的理想前驱体.

为此, 通过结合功能多孔碳基材料的限域作用及MOF-253和超细Pt纳米单晶的优势, 本文合成了MOF-253衍生氮掺杂 碳 $(\mathrm{N} / \mathrm{C})$ 限域的Pt纳米单晶 $(\mathrm{Pt} @ \mathrm{~N} / \mathrm{C}$ )核壳型电催化剂. 制备的Pt-N-C框架不仅具有超薄的氮掺杂活性多孔碳保护层壳体 (平均厚度为 $0.51 \mathrm{~nm}$ ), 还有具高度分散和稳定化的Pt纳米单晶核体; 值得指出的是, 因受到碳层的限域作用, 即使经 $900{ }^{\circ} \mathrm{C}$ 的高温处理, Pt纳米单晶仍保持了较小的晶体尺寸 (平均粒径仅为 $6.7 \mathrm{~nm}$ ); 此外, 该催化剂的 Pt载量较低, 仅为 $6.1 \mathrm{wt} \%$ (Pt@N/C-10). 将其作为OER电催化剂, 表现出优异的OER性能: 在 $10 \mathrm{~mA} \mathrm{~cm}$ 电流密度下, 其过电位仅为 $298 \mathrm{mV}$, 低于商 业 $\mathrm{IrO}_{2}$ 催化剂(353 mV); 而且, 经2000周加速电位扫描后, 其电位仅降低19.4 mV, 也低于 $\mathrm{IrO}_{2}(23.3 \mathrm{mV})$. 本文很好地证明了 通过构建空间限域结构可以有效解决Pt等金属催化剂因表面氧化而导致OER动力学活性和稳定性低的问题.

关键词: Pt, MOF-253; 碳限域; 氧析出反应; 电催化剂

收稿日期: 2019-10-06. 接受日期: 2019-11-23. 出版日期: 2020-05-05.

*通讯联系人. 电话: (027)87651837; 传真: (027)87879468; 电子信箱: msc@whut.edu.cn

†共同第一作者.

基金来源：国家自然科学基金(51672204); 国家重点研发计划课题(2016YFA0202603).

本文的电子版全文由Elsevier出版社在ScienceDirect上出版(http://www.sciencedirect.com/science/journal/18722067). 